\title{
ASYMPTOTICALLY SELF-SIMILAR GLOBAL SOLUTIONS FOR HARDY-HÉNON PARABOLIC SYSTEMS
}

\author{
BYRAME BEN SLIMENE
}

Abstract. In this paper we study the nonlinear parabolic system $\partial_{t} u=\Delta u+a|x|^{-\gamma}|v|^{p-1} v, \partial_{t} v=$ $\Delta v+b|x|^{-\rho}|u|^{q-1} u, t>0, x \in \mathbb{R}^{N} \backslash\{0\}, N \geqslant 1, a, b \in \mathbb{R}, 0 \leqslant \gamma<\min (N, 2), 0<\rho<$ $\min (N, 2), p, q>1$. Under conditions on the parameters $p, q, \gamma$ and $\rho$ we show the existence and uniqueness of global solutions for initial values small with respect of some norms. In particular, we show the existence of self-similar solutions with initial value $\Phi=\left(\varphi_{1}, \varphi_{2}\right)$, where $\varphi_{1}$, $\varphi_{2}$ are homogeneous initial data. We also prove that some global solutions are asymptotic for large time to self-similar solutions.

Mathematics subject classification (2010): 35B40, 35B30, 35K58, 35K67, 35K57, $35 \mathrm{~B} 33$.

Keywords and phrases: Nonlinear heat equation, Hardy-Hénon parabolic system, global existence, self-similar solutions, large time behavior.

\section{REFERENCES}

[1] B. Ben SLImene, S. TAYACHI AND F.B.WeissLeR, Well-posedness, global existence and large time behavior for Hardy-Hénon parabolic equations, Nonlinear Anal., 152 (2017), pp. 116-148.

[2] H. BREZIS AND T. CAZENAVE, A nonlinear heat equation with singular initial data, J. Analyse Math., 68 (1996), pp. 277-304.

[3] M. CAnnone, A generalization of a theorem by Kato on Navier-Stokes equations, Rev. Math. Ib., 13 (1997), pp. 515-541.

[4] M. Cannone, Y. Meyer and F. Planchon, Solutions autosimilaires des équations de Navier-Stokes, Séminaire "Équations aux Dérivées Partielle" de l'école polytechnique, Exposé VIII, 1993-1994.

[5] T. CAZENAVE AND F. B. WeIsSler, Asymptotically self-similar global solutions of the nonlinear Shrödinger and heat equations, Math. Z., 228 (1998), pp. 83-120.

[6] T. Cazenave, F. Dickestein And F. B. Weissler, An equation whose Fujita critical exponent is not given by scaling, Nonlinear Anal., 68 (2008), pp. 862-874.

[7] Y. Giga And T. MiYaKaWA, Navier-Stokes flow in $\mathbb{R}^{3}$ with measures as initial vorticity and Morrey spaces, Comm. in PDE., 14 (1989), pp. 577-618.

[8] T. Kato, Strong $L^{p}$-solutions of the Navier-Stokes equation in $\mathbb{R}^{m}$, with applications to weak solutions, Math. Z., 187 (1984), pp. 471-480.

[9] H. Fujita And T. Kato, On the Navier-Stokes initial value problem , Arch. Rational Mech. Anal., 16 (1964), pp. 269-315.

[10] H. Fujita And T. Kato, On the non stationary Navier-Stokes system, Rend. Sem. Math. Univ. Padova, 32 (1962), pp. 243-260.

[11] Q. H. Phan, Singularity and blow-up estimates via Liouville-type theorems for Hardy-Hénon parabolic equations, J. Evol. Equ., 13 (2013), pp. 411-442.

[12] Q. H. Phan AND PH. Souplet, Liouville-type theorems and bounds of solutions of Hardy-Hénon equations, (English) [J] J. Differential Equations, 252 (2012), pp. 2544-2562 .

[13] S. SNOUSSI and S. TAYACHI, Asymptotic self-similar behavior of solutions for a seminlinear parabolic system, Comm. Cont. Math., 3 (2001), pp. 363-392.

[14] S. SNOUSSI, S. TAYACHI AND F. B. WeIsSLER, Asymptotically self-similar global solutions of a semilinear parabolic equation with a nonlinear gradient term, Proc. Royal Soc. Edinburgh Sect. A, 129 (1999), pp. 1291-1307. 
[15] S. SNOUSSi, S. TAYACHI AND F. B. WeIsSLER, Asymptotically self-similar global solutions of a general semilinear heat equation, Math. Ann., 321 (2001), pp. 131-155.

[16] S. SNOUSSI AND S. TAYACHI, Global existence, asymptotic behavior and self-similar solutions for a class of semilinear parabolic systems, Nonlinear Anal., 48 (2002), pp. 13-53.

[17] X. WANG, On the Cauchy problem for reaction-diffusion equations, Trans. Amer. Math. Soc., 337 (1993), pp. 549-590.

[18] Y. YamaUCHI, Blow-up results for a reaction-diffusion system, Methods Appl. Anal., 13 (2006), pp. $337-350$. 